\title{
SYNTHESIS OF GRAPHENE VIA CHEMICAL VAPOUR DEPOSITION ON COPPER SUBSTRATES WITH DIFFERENT THICKNESSES
}

\author{
Mücahit YILMAZ ${ }^{1, *}$, Yasin Ramazan EKER ${ }^{2}$ \\ ${ }^{1}$ Department of Metallurgical and Material Science, A. Cengiz Engineering Faculty, Necmettin Erbakan \\ University Seydişehir / Konya, Turkey \\ ${ }^{2}$ Department of Metallurgical and Material Science, Faculty of Engineering-Architecture, Necmettin Erbakan \\ University Konya, Turkey
}

\begin{abstract}
The quality of the graphene grown on the top and subside of copper substrate with different thicknesses was investigated. Graphenes were grown on the 9, 25, 150 and $250 \mu \mathrm{m}$ thickness copper substrates with Low-Pressure CVD by using $\mathrm{CH}_{4}$ process gas. Copper substrates were examined through XRD/XRF analysis. Graphenes that are grown on the surface of the copper substrate were characterized by Raman spectrometer. The results show that the grain size calculated from XRD data is decreasing as the thickness increases except for $25 \mu \mathrm{m}$ thick copper. Besides the micro-strain in the structure is increasing according to the thickness of substrate. Raman spectroscopy results show that the graphene grown on the top surface of the 9 $\mu \mathrm{m}$ thick substrate is purely single-layer. The other samples consist of not only single-layer graphene but also few-layer graphene domains. When we look at $\mathrm{I}_{2 \mathrm{D}} / \mathrm{I}_{\mathrm{G}}$ ratios for samples on the top surface of coppers, the graphene doping decreases together with increasing thickness of substrate. At the same time, graphenes on the copper subsurface have blueshift and higher FWMH values. It reveals there is a close relation between the graphene and the copper subsurface. The graphene grown on the top side of the $150 \mu \mathrm{m}$ copper has the typical attribute of suspended single-layer graphene with the redshift of a narrow $2 \mathrm{D}$ peak and $\mathrm{I}_{2 \mathrm{D}} / \mathrm{I}_{\mathrm{G}} \approx 4$. In this study, the best sample is obtained on the top surface of the $150 \mu \mathrm{m}$ thick copper substrate. The large single-layer graphene is depend on microstrain rather than grain orientation.
\end{abstract}

Keywords: Single-layer graphene, CVD graphene growth, Copper substrate

\section{INTRODUCTION}

The hybridization of carbon atoms is at the origin of numerous carbonaceous allotrope, from which graphene was successfully isolated in 2004 by Geim and Novoselov [1]. Single-layer graphene consists of honeycomb arranged $\mathrm{sp}^{2}$ hybridized carbon atoms that are $142 \mathrm{pm}$ distanced from each other [2]. The $\pi$ bond resonance within the whole structure gives exceptional properties like $250000 \mathrm{~cm}^{2} . \mathrm{V}^{-1} \cdot \mathrm{s}^{-1}, 1 \mathrm{TPa}$ young modulus and $5000 \mathrm{~W} \cdot \mathrm{m}^{-1} \cdot \mathrm{K}^{-1}$ thermal conductivity $[3,4]$. Therefore, several application domains like gas sensors, solar cells, transistors or energy storage devices are taken into account in the literature studies [5-13].

The synthesis of graphene is possible either via physical methods such as mechanical exfoliation or via chemical methods such as Hummer's Methods and chemical vapour deposition [14-17]. However, chemical vapour deposition (CVD) is one of the mostly preferred methods to synthesize large single layer graphene $[18,19]$. During the CVD process hydrocarbon gas like methane or acetylene is firstly decomposed under high temperature, then collected on copper or nickel substrate surface where the graphene formation starts. The solubility of carbon in nickel is better than that of copper. Because of this, copper substrate is preferred for single layer graphene. The formation mechanism is strongly depend on the affinity between carbon and substrate [20,21]. 
The surface state and the crystal orientation of the copper substrate have been studied in the literature. The electro-polishing is one of the best cleaning processes to get smooth surface favoring the formation of large single-layer graphene [22-24] compared to the standard cleaning processes. Another way to reduce defects on the copper surface is to use substrate where low-index crystal orientation is present, especially $\mathrm{Cu}(111)$ of which defect rate is very low [25-29]. The purpose of selecting the substrate choice is to obtain as much as large and perfect single layer graphene which can be transferable to diverse substrates. Finally, the last contribution to the formation of large single-layer domain is to reduce cracks involved by $2 \%$ copper volume difference between the synthesis temperature at about $1000^{\circ} \mathrm{C}$ and the room temperature after synthesis [30].

The purpose of this study is to determine which copper foils are commercially viable on the market and which are more suitable for producing single-layer graphene.

\section{MATERIALS AND METHODS}

The materials and methods involved the preparation of copper foils, growth of graphene and characterization of graphene.

Preparation of copper foils: $9 \mu \mathrm{m}$ (MTI Part\# EQ-bccf-9u), $25 \mu \mathrm{m}$ (Alfa Aesar Part\# 46986), $150 \mu \mathrm{m}$ (Sigma Aldrich Part\# GF43898563) and $250 \mu \mathrm{m}$ (Sigma Aldrich Part\# 349178) thick copper foils were cut properly in $1 \mathrm{~cm}^{2}$ size. They were electro-polished by using an acidic solution in which the anode is a pure thick copper foil anchored by an alligator clip. The cathode attached by an alligator clip is the copper devoted to be the substrate for the graphene growth. The cathode is held parallel to the anode when a voltage of $4.0 \mathrm{~V}$ and a current of $1.0 \mathrm{~A}$ are applied for 90 seconds. After the electro-polishing, copper foils were rinsed with deionized (DI) water, further washed with isopropyl alcohol (IPA), and then blow-dried under $\mathrm{N}_{2}$.

Growth of graphene: Graphene growth was performed within the MTI OTF-1200X model CVD system. Before loading $\mathrm{Cu}$ foils into the middle of furnace, a polished quartz substrate holder was rinsed with acetone afterward with IPA, and finally dried with $\mathrm{N}_{2}$. The quartz slide was placed into the central heat zone of the furnace using a clean glass rod. After the loading, the chamber was pumped down to 100 mTorr for 5 minutes (to remove $\mathrm{O}_{2}$ ), brought to 20 Torr pressure and stabilized with a flow of $100 \mathrm{sccm}$ (Standard Cubic Centimeters per Minute) $\mathrm{Ar}$ and $50 \mathrm{sccm} \mathrm{H}_{2}$. The furnace was heated up to $1000^{\circ} \mathrm{C}$ within $45 \mathrm{~min}$ and kept at this temperature for $25 \mathrm{~min}$ (annealing) to increase the grain size of the copper foil, to reduce copper oxide and to remove organic residues of $\mathrm{Cu}$ foil before the growth process begins. The growth process was started by switching off the Ar. At the same time $\mathrm{H}_{2}$ flow was raised to 400 sccm, after that $\mathrm{CH}_{4}$ gas valve was switched on at the rate of $200 \mathrm{sccm}$. After 5 minutes, $\mathrm{CH}_{4}$ flow was switched off and $\mathrm{H}_{2}$ flow was reduced to $50 \mathrm{sccm}$. Ar flow was switched on at $100 \mathrm{sccm}$ flow rate. The CVD furnace was cooled from a rate of $50{ }^{\circ} \mathrm{C} / \mathrm{min}$ to the room temperature.

Characterization of graphene: Characterization of the structural properties of the copper substrates were made through GNR ADP PRO 2000 model X-ray diffraction system (XRD) by using $\mathrm{Cu}_{\mathrm{K} \alpha}$ radiation source $\left(\lambda=1.5406 \AA\right.$ ) with $0.02^{\circ}$ step and $2 \theta$ between $10^{\circ}$ and $80^{\circ}$. Their elemental analysis was made with RIGAKU NEX_CG model X-ray fluorescence spectrometer (XRF) by using RX9 (0-2.8 keV), Cu (2.8-7.5 keV), Mo (5.5-15 keV) and Al (16-38 keV) X-ray sources. The graphene on the copper foils' top surface and subsurface were characterized via RENISHAW INVIA REFLEX Confocal (x100 objective) Raman spectrometer with 1800 lines/mm grating and $532 \mathrm{~nm}$ excitation energy at $200 \mathrm{~mW}$ laser power. 


\section{RESULTS AND DISCUSSION}

\subsection{Elemental and Structural Investigation of the Copper Substrates}

During the CVD graphene growth process, copper act both as substrate and catalyst. Therefore, surface morphology, crystalline orientation and purity are influencing the graphene formation. The 9, 25, 150, and $250 \mu \mathrm{m}$ thickness of copper substrate purity was analyzed via XRF spectroscopy which cannot distinguish elements with atomic mass below 23 (sodium). Thus, for each copper substrate the elemental analysis shown in Table 1 gives the weight percent of copper and the others.

Table 1. XRF spectroscopy results of different thickness copper substrates

\begin{tabular}{ccccc}
\hline & $\begin{array}{c}\mathbf{9} \boldsymbol{\mu m} \\
\text { thickness }\end{array}$ & $\begin{array}{c}\mathbf{2 5} \boldsymbol{\mu m} \\
\text { thickness }\end{array}$ & $\begin{array}{c}\mathbf{1 5 0} \boldsymbol{\mu m} \\
\text { thickness }\end{array}$ & $\begin{array}{c}\mathbf{2 5 0} \boldsymbol{\mu m} \\
\text { thickness }\end{array}$ \\
\hline Copper mass (\%) & 99.90 & 99.90 & 99.90 & 99.90 \\
Other mass (\%) & 0.10 & 0.10 & 0.10 & 0.10 \\
\hline
\end{tabular}

The copper foil purity announced by the providers is $\sim 99.95 \%$ except $25 \mu \mathrm{m}$ copper foil, but the results indicated a purity of $\sim 99.9 \%$. Since, all the preparation of experiment and analysis are applied in the atmospheric environment, decreasing purity can be explained by the formation of copper oxide compounds like $\mathrm{Cu}_{2} \mathrm{O}$ and $\mathrm{CuO}$ which have melting points of $1235^{\circ} \mathrm{C}$ and $1330{ }^{\circ} \mathrm{C}$ respectively [31]. At the $1000{ }^{\circ} \mathrm{C}$ process temperature, oxide forms of copper cannot evaporate, therefore purification of copper is not possible during the growth of graphene [32].

The XRD patterns of different thickness copper substrates are normalized and indexed [33] to obtain more intensive peak as shown in Figure 1, and the measured peak intensities are presented in the Figure 2. The structure of the elemental form of copper is face-centered cubic (fcc), the size of its unit cell is $0.362 \mathrm{~nm}$, its space group is Fm-3m and number of its space group is 225 [26]. As seen in Figure 1, all indices for each peak are even or odd. It requires that the scattering factor $\left(\mathrm{F}_{\mathrm{hkl}}\right)$ is equal to $4 \mathrm{f}$. Since the $F_{\text {hkl }}$ of the fcc structure is equal to $4 \mathrm{f}$, all of copper substrates have fcc crystal structure. However, the crystal orientations of copper substrates are similar for three copper foils $(25,150$ and $250 \mu \mathrm{m})$ and for (200) plane except one $(9 \mu \mathrm{m})$. While (111) peak is dominant for $9 \mu \mathrm{m}$ thick copper substrate, $(200)$ peak is dominant for 25,150 and $250 \mu \mathrm{m}$ thick copper substrates. The orientation of the $25 \mu \mathrm{m}$ thick copper substrate is perfect because of its intensity shown as Figure 2. 


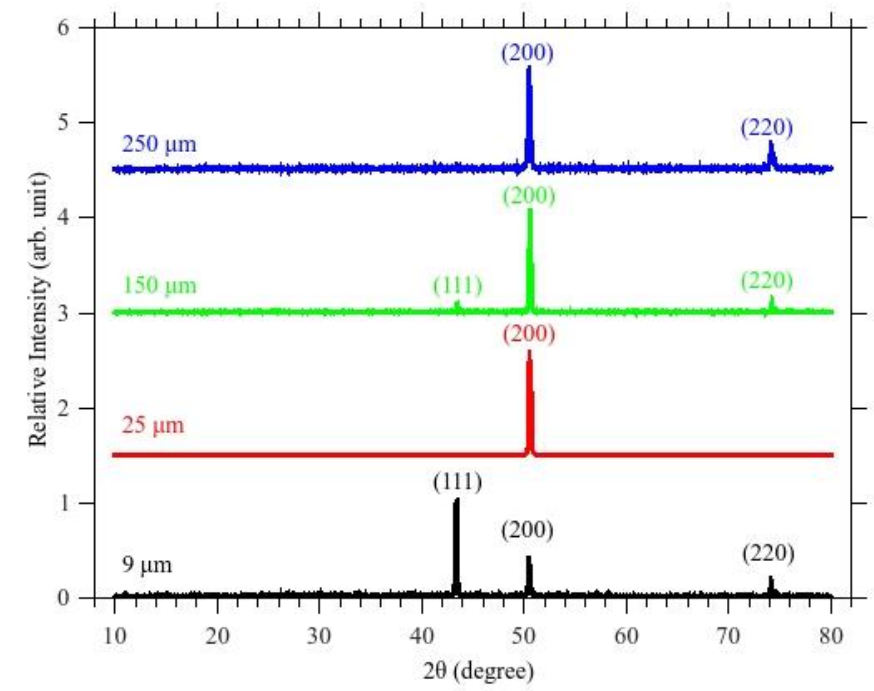

Figure 1. Normalized XRD patterns of $9 \mu \mathrm{m}, 25 \mu \mathrm{m}, 150 \mu \mathrm{m}$, and $250 \mu \mathrm{m}$ thickness copper substrates

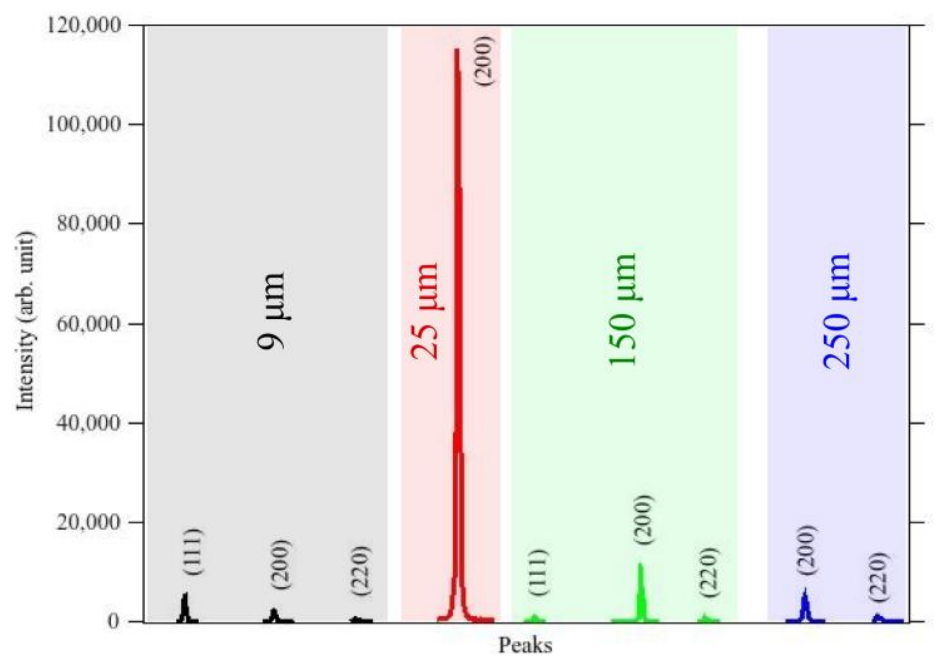

Figure 2. XRD peak intensities of $9 \mu \mathrm{m}, 25 \mu \mathrm{m}, 150 \mu \mathrm{m}$, and $250 \mu \mathrm{m}$ thickness copper substrates

The average crystallite size in the form of bulk (L) is determined by the Scherrer equation [34] by using the preferred orientation of copper substrates and micro-strain $(\varepsilon)$ [34] values over all peaks as shown Equation (1) and (2).

$$
\begin{aligned}
& L=\frac{K \lambda}{\beta \cos \theta} \\
& \varepsilon=\frac{\beta}{4 \tan \theta}
\end{aligned}
$$

$\beta$ is the peak width of the diffraction peak profile at half maximum (FWHM) height resulting from small crystallite size in radian and calculated by Analysis of Variance (ANOVA), $\lambda$ is the X-ray wavelength in nanometer, $\mathrm{K}$ is constant related to crystallite shape, normally taken as 0.89 for cubic unit cell and $\theta$ is the peak position known as Bragg's angle. Calculated size of particles and micro-strain values of copper substrates are given in Table 2 . 
Yllmaz and Eker / Anadolu Univ. J. of Sci. and Technology A-Appl. Sci. and Eng. 18 (2) - 2017

Table 2. Structural parameters calculated from main peak of XRD patterns of different thickness copper substrates

\begin{tabular}{ccccc}
\hline & $\begin{array}{c}\mathbf{9} \boldsymbol{\mu m} \\
\text { thickness }\end{array}$ & $\begin{array}{c}\mathbf{2 5} \boldsymbol{\mu m} \\
\text { thickness }\end{array}$ & $\begin{array}{c}\mathbf{1 5 0} \boldsymbol{\mu m} \\
\text { thickness }\end{array}$ & $\begin{array}{c}\mathbf{2 5 0} \boldsymbol{\mu m} \\
\text { thickness }\end{array}$ \\
\hline $\boldsymbol{\beta}$ (degree) & 0.52973 & 0.20335 & 0.41067 & 0.71152 \\
$\boldsymbol{\theta}($ degree $)$ & 43.38 & 50.54 & 50.56 & 50.50 \\
$\mathbf{L}(\mathbf{n m})$ & 3,14 & 7,01 & 3,49 & 1,98 \\
$\boldsymbol{\varepsilon}$ & $-0,19$ & 0,18 & 0,34 & 0,74 \\
\hline
\end{tabular}

Where plastic deformation occurs, the local distortion of lattice planes give rise to non-uniform variations in the inter planar spacing called as micro-strain. Micro-strains of copper substrates are calculated by Williamson-Hall method shown as Equation (2) [35]. A positive value of micro-strain reveals that the distance of the relevant crystal planes are not identical, possibly due to the presence of defects and stress. A negative value of micro-strain indicates the broadening of small internal strain, therefore results show that there is comprehensive strain in the crystal lattice of the examined material.

\subsection{Raman Analysis of Synthesized Graphenes}

Raman Spectroscopy is an efficient analyzation to determine the properties of graphene sample especially with the 3 main peaks observed at about $1350 \mathrm{~cm}^{-1}$ (D peak), $1580 \mathrm{~cm}^{-1}$ (G peak) and 2700 $\mathrm{cm}^{-1}$ [36]. The G-band is formed through the bond stretching of all pairs of $\mathrm{sp}^{2}$ atoms in both rings and chains $\left(\mathrm{E}_{2 \mathrm{~g}}\right.$ phonon at the Brillouin zone center) [37,38]. As the D-band is proportional to the breathing modes of $\mathrm{sp}^{2}$ atoms in rings, it gives an idea about the material defects ( $\mathrm{sp}^{3}$ carbons) [39]. Finally, the 2D-band is induced by the double resonant Raman scattering with 2-phonon emission [36,39]. Figure 3 shows that the characteristic Raman peaks for the synthesized graphenes.

Typically, single-layer graphene is characterized by a successful fitting of the 2D-peak with a single Lorentzian $[36,38,40]$. While for double-layer graphene, the 2D-peak is fitted with four Lorentzian $\left(2 \mathrm{D}_{1 \mathrm{~B}}, 2 \mathrm{D}_{1 \mathrm{~A}}, 2 \mathrm{D}_{2 \mathrm{~A}}, 2 \mathrm{D}_{2 \mathrm{~B}}\right)$ and for higher graphene layer, the fitting peak is comparable to one of the graphites with two Lorentzian peaks $\left(\mathrm{D}_{1}\right.$ and $\left.\mathrm{D}_{2}\right)$ [36,41,42]. Of these, $2 \mathrm{D}_{1 \mathrm{~A}}$ and $2 \mathrm{D}_{2 \mathrm{~A}}$ have higher relative intensities than the other two. As the number of layers increases, a significant decrease in the intensity of low frequency $2 \mathrm{D}_{1}$ peak occurs. Deconvolution of the 2D-peaks of all samples are highly completed with a coefficient of determination $\left(\mathrm{R}^{2}\right)$ at around 0,999 (Table 3). For all samples, a high intensity single Lorentzian peak is dominant (Figure 4). According to the peaks, there is one Lorentzian peak only the graphene synthesized on the top surface of the $9 \mu \mathrm{m}$ thick substrate. But, this is insufficient to say that it is a purely graphene. For the other samples, Lorentzian peaks with lower intensities need to reach high $\mathrm{R}^{2}$, which indicates not only the presence of single-layer graphene, but also few-layer graphene. Moreover, the G-peak intensities are decreasing as the thickness of copper increases, which illustrates the expansion of multi-layer graphene domains (Figure 5) [43,44]. However, the G-peak intensity is not sufficient to determine the exact number of stacked layer [42], instead its ratio with the 2D-peak intensity $\left(\mathrm{I}_{2 \mathrm{D}} / \mathrm{I}_{\mathrm{G}}\right)$ is more characteristic [19]. In the literature, a reference value of $\mathrm{I}_{2 \mathrm{D}} / \mathrm{I}_{\mathrm{G}} \approx 4$ is accepted for suspended (not supported) single-layer graphene [36,45]. However, this value can change according to the doping level of the graphene sample. A low doping level results in an increase from about 4 to around 9, while this ratio decreases from about 4 to around 1 at a high doping ratio [36,46,47]. In the light of these informations, it can be said to be a perfect graphene on the top surface of the 150 $\mu \mathrm{m}$ thick substrate owing to its $I_{2 \mathrm{D}} / \mathrm{I}_{\mathrm{G}}$ ratio is almost equal to 4 .

In this study, only the spectrum of the graphene synthesized at the subsurface of the $150 \mu \mathrm{m} \mathrm{Cu}$ foil contains D-peak (Figure 3). In other words, except this sample, the others contain sigle and bilayer graphene layers with fewer defects. However, the examination of the peak shapes (fitting Lorentzian peak and Full Width at Half Maximum FWHM) revealed that, their intensity ratio $\left(\mathrm{I}_{2 \mathrm{D}} / \mathrm{I}_{\mathrm{G}}\right)$ and wave number (shift to high value (blueshift) or to lower value (redshifts)) are required to evaluate the characteristics of the sample $[43,48]$. 

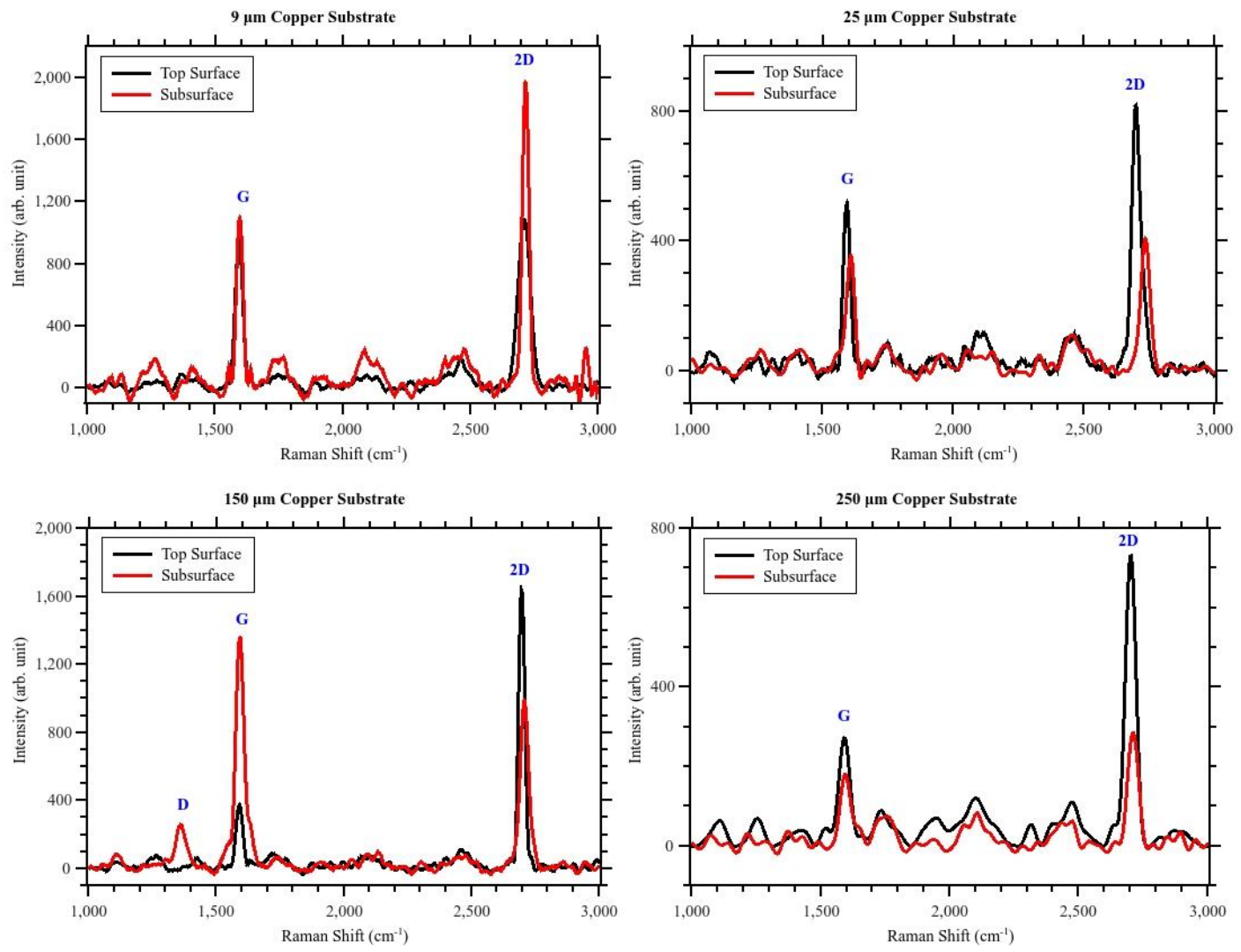

Figure 3. Raman Spectrum of graphenes taken from the top surface and subsurface of 9, 25, 150 and $250 \mu \mathrm{m}$ thick copper substrates

During their pre-treatment before growth, only the top surface of substrates is faced with the electropolishing anode. Moreover, only top surfaces are directly exposed to the gases during the growth while subsurfaces are in contact with quartz plate. For these reasons, $\mathrm{I}_{2 \mathrm{D}} / \mathrm{I}_{\mathrm{G}}$ values must be compared separately for synthesized graphene on each substrate surface. The $I_{2 D} / I_{G}$ ratios of graphenes that are grown between substrate subsurface and quartz plate are below the value 2, which indicates a high doping level. However, for the graphenes that are grown on the copper top surfaces, the $\mathrm{I}_{2 \mathrm{D}} / \mathrm{I}_{\mathrm{G}}$ values are progressively increasing from 1.15 to 9.93 as the thickness increases. It reveals that the values for doped graphene sample is changing according to the thickness of the substrate (Table 3).

Table 3. Position of 2D and G peaks, FWHMs, intensities and coefficients of determination

\begin{tabular}{|c|c|c|c|c|c|c|c|c|}
\hline & $\begin{array}{c}\text { 2D Peak } \\
\text { Position } \\
\left(\mathrm{cm}^{-1}\right)\end{array}$ & $\begin{array}{c}\text { FWHM } \\
(2 \mathrm{D})\left(\mathrm{cm}^{-1}\right)\end{array}$ & $\begin{array}{l}\text { Int. } \\
\text { I }_{2 \mathrm{D}}\end{array}$ & $\begin{array}{c}\text { G Peak } \\
\text { Position } \\
\left(\mathrm{cm}^{-1}\right)\end{array}$ & $\begin{array}{l}\text { FWHM } \\
(\mathbf{G})\left(\mathrm{cm}^{-1}\right)\end{array}$ & $\begin{array}{c}\text { Int. } \\
\text { I }_{G}\end{array}$ & $\mathbf{I}_{2 \mathrm{D}} / \mathbf{I}_{\mathbf{G}}$ & $\begin{array}{c}\mathbf{R}^{2} \\
(2 \mathrm{D})\end{array}$ \\
\hline $9 \mu \mathrm{m}$ - top surface & 2711 & 56 & 1087 & 1590 & 35 & 944 & 1.15 & 0.9993 \\
\hline $9 \mu \mathrm{m}$ - subsurface & 2716 & 32 & 1969 & 1593 & 31 & 1092 & 1.80 & 0.9987 \\
\hline $25 \mu \mathrm{m}$ - top surface & 2698 & 36 & 819 & 1590 & 32 & 516 & 1.59 & 0.9991 \\
\hline $25 \mu \mathrm{m}$ - subsurface & 2735 & 41 & 408 & 1606 & 38 & 355 & 1.15 & 0.9990 \\
\hline $150 \mu \mathrm{m}$ - top surface & 2695 & 25 & 1633 & 1588 & 33 & 375 & 4.35 & 0.9988 \\
\hline $150 \mu \mathrm{m}$ - subsurface & 2707 & 38 & 988 & 1590 & 38 & 1358 & 0.73 & 0.9997 \\
\hline $250 \mu \mathrm{m}$ - top surface & 2702 & 40 & 2702 & 1588 & 51 & 272 & 9.93 & 0.9996 \\
\hline $250 \mu \mathrm{m}$ - subsurface & 2708 & 41 & 285 & 1590 & 49 & 180 & 1.59 & 0.9995 \\
\hline
\end{tabular}


Yılmaz and Eker / Anadolu Univ. J. of Sci. and Technology A-Appl. Sci. and Eng. 18 (2) - 2017
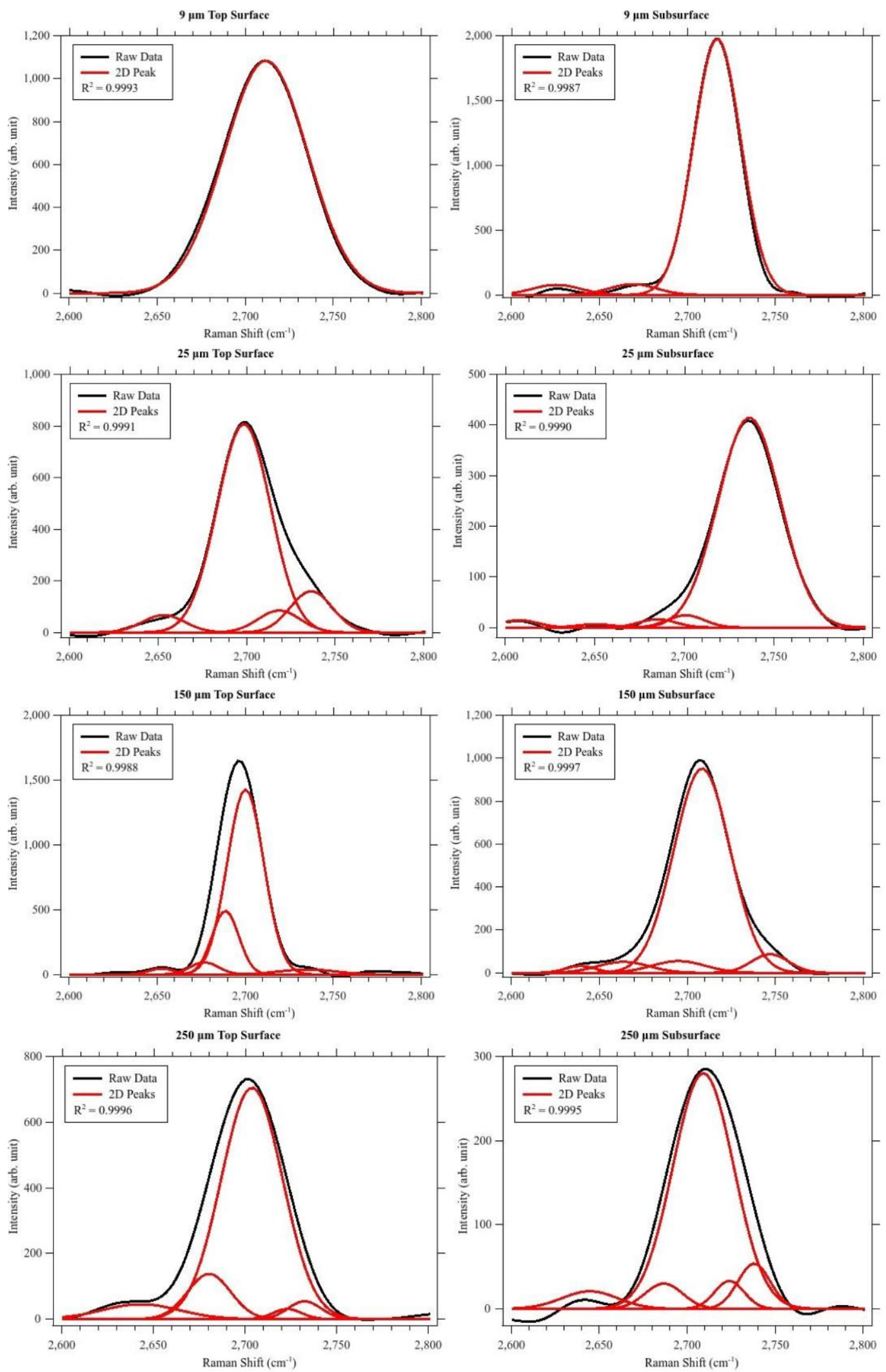

Figure 4. 2D Raman peak deconvolution of graphenes synthesized on the top surface and the subsurface of $9,25,150$ and $250 \mu \mathrm{m}$ thick copper substrate 
In addition, the change in the charge density of graphene contributes to the shifting of $\mathrm{G}$ and $2 \mathrm{D}$ bands based on the electron-phonon coupling $[41,49]$ which affects the $\mathrm{I}_{2 \mathrm{D}} / \mathrm{I}_{\mathrm{G}}$ ratio (see Figure 6 ). The reason of this shifting might be the presence of multi-layer graphene [42], the interaction with the substrate [46], the electron/hole doping [50], the straining on graphene [42, 51,52] or the temperature at which heat treatment is applied [53]. In the Raman spectrum of the present samples, generally both 2D and G peaks shift to the blue i.e. to higher wave number. Several reasons can be attributed for the blueshift of peak such as (i) the disorder in the multi-layer domains [41,43], (ii) the hole doping [43, 45, 51], (iii) the supported graphene $[36,39,51]$ or (iv) the comprehensive straining after heat treatment $[42,52]$. Since blueshift amplitude and FWHM are globally higher for subsurface graphene, a close relationship between the graphene and the copper subsurface is observed $[39,54]$.
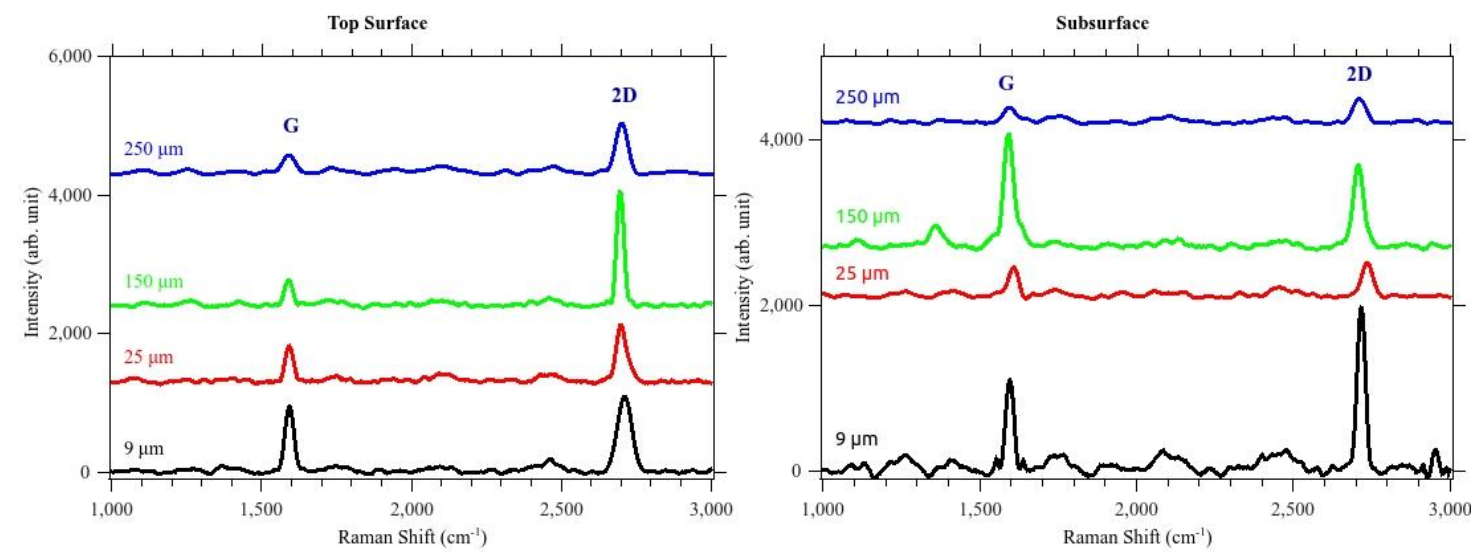

Figure 5. Comparison of Raman Spectrum of graphenes deposited on top surface and subsurface of copper substrates with various thickness
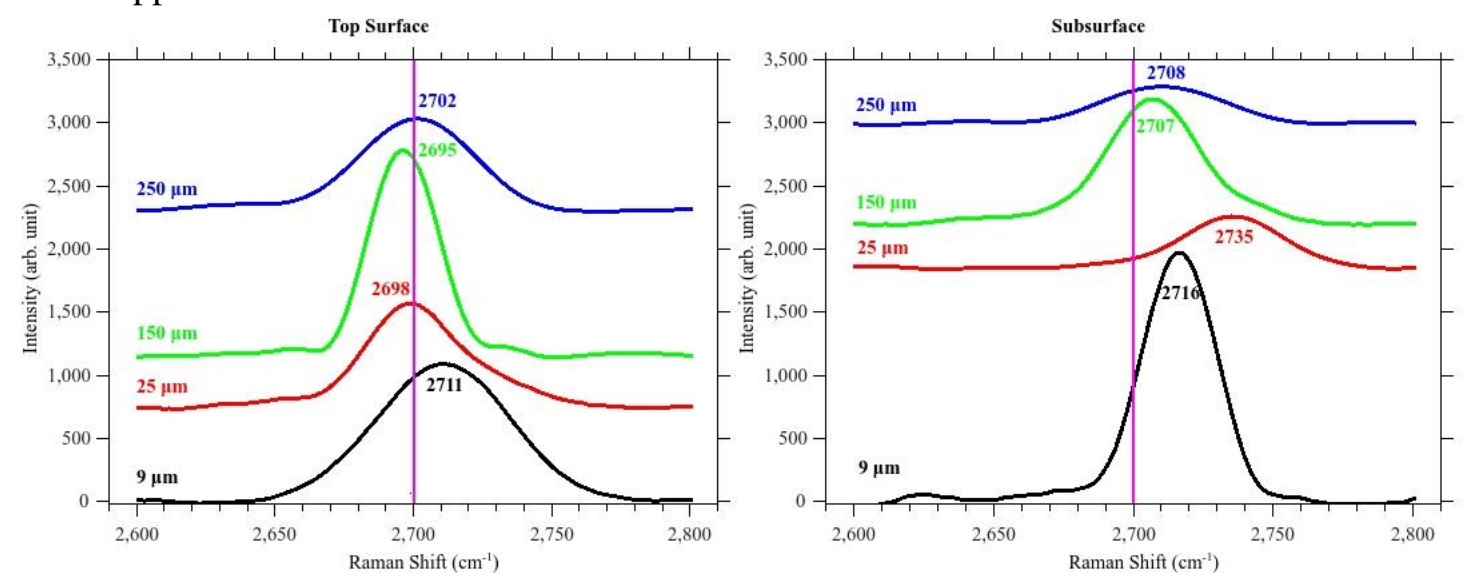

Figure 6. Shifting of 2D Raman peak of graphenes synthesized on top surface and subsurface of 9, 25, 150 and $250 \mu \mathrm{m}$ thick copper substrates

As the XRD data results show, the biggest grains are present within the $25 \mu \mathrm{m}$ thick copper, while the smallest within the $250 \mu \mathrm{m}$ thick copper. When the (200) orientation is based, the grain size decreases as the thickness increases. Thus, the micro-strain in the structure increases together with the increase in thickness. This confirms the fact that presence of smallest grain involves a multiplication of grain number, therefore more grain boundaries are present which results in an increase of the strain in the structure. The amplitude of this effect depends on the orientation of grains, since the absolute value of the strain for the $9 \mu \mathrm{m}$ and $25 \mu \mathrm{m}$ thickness copper are comparable.

On the other hand the substrate thickness as well as the surface where graphene is grown has a noticeable effect on the graphene doping. For the graphene grown on the top surface of the copper, the $\mathrm{I}_{2 \mathrm{D}} / \mathrm{I}_{\mathrm{G}}$ values 
increase from 1.15 to 9.93 as the thickness increases. It reveals that the sample doping decreases when thickness increases. Moreover, for the graphenes grown on the top surface of the $25 \mu \mathrm{m}$ and the top surface of the $150 \mu \mathrm{m}$ copper foils, small redshift of the 2D peak is observed. This is the characteristic of the multi-layered graphene domains and/or suspended graphene. Especially, the graphene grown on the top surface of the $150 \mu \mathrm{m}$ copper has the typical attribute of suspended single-layer graphene with the redshift of a narrow $2 \mathrm{D}$ peak and $\mathrm{I}_{2 \mathrm{D}} / \mathrm{I}_{\mathrm{G}} \approx 4$.

Concerning the graphene grown on the subsurface, the doping effect is related not only to the substrate properties but also toe neighboring of the quartz holder. For this reason several doping factors are involved. Furthermore, an investigation of peak shifts and FWMH is helpful to determine the graphene doping. The general presence of high blueshift amplitude and FWMH specifies a firm relation between the graphene and the copper subsurface.

\section{CONCLUSION}

By the CVD method the graphene is grown both on the top surface and subsurface of copper substrates with different thicknesses that are electro-polished and annealed. Samples mainly consist of large singlelayer domain. Unfortunately they often include small multi-layer domains. The Raman spectroscopy results indicated that the graphene grown on the top surface of the $150 \mu \mathrm{m}$ thick substrate is purely single-layer. The other samples have not only single-layer graphene but also domains with few-layer graphene which can be attributed to the effect of preferential grain orientation (111) confirmed by the literature results. These parameters are the sources of copper surface morphology irregularities. Concerning the samples synthesized between the copper subsurface and quartz support, high doping properties are characterized by marked peak shifts and no correlation is found with the copper properties. The free carbon diffusion is a key parameter to obtain good quality sample. In this study, the best sample is obtained on the top surface of the $150 \mu \mathrm{m}$ thick copper substrate. It shows that more than the grain orientation, micro-strain that is decreasing within the substrate is a key factor to grow large single-layer graphene. The use of pure and mono-crystalline copper substrate can be a solution to fully integrated single-layer graphene for the development of new technologies. However, growing graphene on thick copper foil also brings with it a number of disadvantages such as the duration of the etching time during the transfer process and the cost.

\section{ACKNOWLEDGEMENTS}

This work was supported by Necmettin Erbakan University BAP Coordination Office under the project number: 121210005.

\section{REFERENCES}

[1] Geim AK, Novoselov KS. The rise of graphene. Nat. Mater. 2007;6:183-191.

[2] Slonczewski JC, Weiss PR. Band structure of graphite. Phys. Rev. 1958;109:272-279.

[3] Novoselov KS, Geim AK, Morozov SV, Jiang D, Zhang Y, Dubonos SV, et al. Electric field effect in atomically thin carbon films. Science. 2004;306:666-669.

[4] Balandin AA, Ghosh S, Bao W, Calizo I, Teweldebrhan D, Miao F, et al. Superior thermal conductivity of single-layer graphene. Nano Lett. 2008;8:902-907.

[5] Fowler JD, Allen MJ, Tung VC, Yang Y, Kaner, RB, Weller BH. Practical chemical sensors from chemically derived graphene. ACS Nano. 2009;3(2):301-306. 
[6] Wang X, Zhi L, Mullen K. Transparent, conductive graphene electrodes for dye-sensitized solar cells. Nano Lett. 2008;8(1):323-327.

[7]Wang F, Zhang Y, Tian C, Girit C, Zettl A, Crommie M, et al. Gate-variable optical transitions in graphene. Science. 2008;320(5873):206-209.

[8] Mueller T, Xia F, Avouris, P. Graphene photodedectors for high-speed optical communications. Nat. Photon. 2010;4:297-301.

[9] Schwierz F. Graphene transistors. Nat. Nanotechnol. 2010;5:487-496.

[10] Xia F, Perebeinos V, Lin YM, Wu Y, Avouris P. The origins and limits of metal-graphene junction. Nat. Nanotechnol. 2011;5:179-184.

[11] Xia F, Farmer DB, Lin YM, Avouris, P. Graphene field-effect transistors with high on/off current ratio and large transport band gap at room temperature. Nano Lett. 2010;10:715-718.

[12] Brownson DAC, Banks CE. Fabricating supercapacitors: highlighting the impact of and moieties. Chem. Commun. 2012:;48:1425-1427.

[13] Wang G, Shen X, Yao J, Park J. Graphene nanosheets for enhanced lithium storage in lithium ion batteries. Carbon. 2009;47(8):2049-2053.

[14] Zhu Y, Murali S, Cai W, Li X, Suk JW, Potts JR, et al. Graphene and graphene oxide: synthesis, properties, and applications. Adv. Mater. 2010;22:3906-3924.

[15] Losurdo M, Giangregorio MM, Capezzuto P, Bruno G. Graphene CVD growth on copper and nickel: role of hydrogen in kinetics and structure. Phys. Chem. Chem. Phys. 2011;13:20836-20843.

[16] Dikin DA, Stankovich S, Zimney EJ, Piner RD, Dommett GHB, Evmenenko G, et al. Preparation and characterization of graphene oxide paper. Nature. 2007;448:457-460.

[17] Bonaccorso F, Lombardo A, Hasan T, Sun Z, Colombo L, Ferrari AC. Production and processing of graphene and 2d crystals. Materialstoday. 2012;15(12):564-589.

[18] Wang C, Chen W, Han C, Wang G, Tang B, Tang C, et al. Growth of millimeter-size single crystal graphene on $\mathrm{Cu}$ foils by circumfluence chemical vapor deposition. Scientific Reports. 2014;4(4537):15 .

[19] Reina A, Jia X, Ho J, Nezich D, Son H, Bulovic V, et al. Lage area, few-layer graphene films on arbitrary substrates by chemical vapor deposition. Nano Lett. 2009;9(1):30-35.

[20] Yu Q, Lian J, Siriponglert S, Li H, Chen YP, Pei SS. Graphene segregated on Ni surfaces and transferred to insulators. Appl. Phys. Lett. 2008;93:113103(3).

[21] Kim KS, Zhao Y, Jang H, Lee SY, Kim JM, Kim KS, et al. Large-scale pattern growth of graphene films for stretchable transparent electrodes. Nature. 2009;457:706-710.

[22] Magnuson CW, Kong X, Ji H, Tan C, Li H, Piner R, et al. Copper oxide as a "self-cleaning" substrate for graphene growth. Journal of Materials Research. 2014;29(3):403-409. 
[23] Luo ZT, Lu Y, Singer DW, Berck E, Somers LA, Goldsmith BR, et al. Effect of substrate roughness and feedstock concentration on growth of wafer-scale graphene at atmospheric pressure. Chem Mater. 2011;23:1441-1447.

[24] Zhang Y, Gao T, Gao Y, Xie S, Ji Q, Yan K, et al. Defect-like structures of graphene on copper foils for strain relief investigated by high-resolution scanning tunneling microscopy. ACS Nano. 2011;5(5):4014-4022.

[25] Gao L, Guest JF, Guisinger NP, Epitaxial graphene on $\mathrm{Cu}(111)$. Nano Lett. 2010;10:3512-3516.

[26] Straumanis ME, Yu LS. Lattice parameters, densities, expansion coefficients and perfection of structure of $\mathrm{Cu}$ and of $\mathrm{Cu}-\mathrm{In} \alpha$ phase. Acta Cryst. 1969;A25:676-682.

[27] Novoselov KS, Geim AK, Morozov SV, Jiang D, Katsnelson MI, Grigorieva IV, et al. Twodimensional gas of massless dirac fermions in graphene. Nature. 2005;438:197-200.

[28] Lee C, Wei X, Kysar JW, Hone J. Measurement of the elastic properties and intrinsic strength of monolayer graphene. Science. 2008;321:385-388.

[29] Balandin AA, Ghosh S, Bao W, Calizo I, Teweldebrhan D, Miao F, et al. Superior thermal conductivity of single-layer graphene. Nano Lett. 2008;8:902-907.

[30] Taylor RE, Ho CY. Thermal expansion of solids. ASM International: Materials. 1998:273.

[31] Richardson HW. Copper compounds in ullmann's encyclopedia of industrial chemistry. Weinheim: Wiley-VCH;2005.

[32] Mack E, Osterhof GG, Kraner HM. Vapor pressure of copper oxide and copper. J. Am. Chem. Soc. 1923;45(3):617-623.

[33] Yu Q, Liu X, Tang D. Extreme extensibility of copper foil under compound forming conditions. Scientific Reports. 2013;3(3556):1-6.

[34] Cullity DB. Elements of X-ray diffraction. Massachusetts: Addison-Wesley;1956.

[35] Suryanarayana C, Grant Norton M. X-Ray diffraction: A practical approach, Springer US; 1998.

[36] Ferrari AC, Meyer JC, Scardaci V, Casiraghi C, Novoselov KS, Geim AK. Raman spectrum of graphene and graphene layers. Phys. Rev. Lett. 2006;97:187401-197404.

[37] Tan PH, Deng Y, Zhao Q. Temperature-dependent raman spectra and anomalous raman phenomenon of highly oriented pyrolytic graphite. Phys. Rev. B. 1998;58:5435-439.

[38] Malard LM, Pimenta MA, Dresselhaus G, Dresselhaus MS. Raman spectroscopy in graphene. Physics Reports. 2009;473:51-87.

[39] Basko DM, Piscanec S, Ferrari AC. Electron-electron interactions and doping dependence of the two-phonon raman intensity in graphene. Phys. Rev. B. 2009;80:165413-165422.

[40] Bunch JS, van der Zande AM, Verbridge SS, Frank IW, Tanenbaum DM, Parpia JM, et al. Electromechanical resonators from graphene sheets. Science. 2007;315:490-493. 
[41] Ferrari AC. Raman spectroscopy of graphene and graphite: disorder, electron-phonon coupling, doping and nonadiabatic effects. Solid State Comm. 2007;143:47-57.

[42] Graf D, Molitor F. Spatially resolved raman spectroscopy of single-and few-layer graphene. Nano Lett. 2007;7:238-242.

[43] Ni Z, Wang Y, Yu T, Shen Z. Raman spectroscopy and imaging of graphene. Nano Res. 2008;1:273-291.

[44] Wang YY, Ni ZH, Shen ZX, Wang HM, Wu YH. Interference enhancement of raman signal of graphene. Appl. Phys. Lett. 2008;92:043121(3).

[45] Tang B, Guoxin H, Gao H. Raman spectroscopic characterization of graphene. Applied Spectroscopy Reviews. 2010;45(5):369-407.

[46] Zhen HN, Ting Y. Probing charged impurities in suspended graphene using raman spectroscopy. ACS Nano. 2009;3:569-574.

[47] Han MY, Özyılmaz B, Zhang Y, Kim P. Energy band-gap engineering of graphene nanoribbons. Phys. Rev. Lett. 2007;98:206805-206808.

[48] Wang YY, Ni ZH, Yu T, Wang HM, Wu YH, Chen W, et al. Raman studies of monolayer graphene: the substrate effect. J. Phys. Chem. C. 2008;112:10637-10640.

[49] Calizo I, Bejenari I. Ultraviolet raman microscopy of single and multilayer graphene. J. Appl. Phys. 2009;106:043509-043513.

[50] Das A, Pisana S, Chakraborty B, Piscanec S, Saha SK, Waghmare UV, et al. Monitoring dopants by raman scattering in an electrochemically top-gated graphene transistor. Nat. Nanotechnol. 2008;3:210-215.

[51] Zhen HN, Ting Y, Yun HL. Uniaxial strain on graphene: raman spectroscopy study and band-gap opening. ACS Nano. 2008;2:2301-2305.

[52] Zhen HN, Hao MW, Yun M. Tunable stress and controlled thickness modification in graphene by annealing. ACS Nano. 2008;2:1033-1039.

[53] Calizo I, Balandin AA, Bao W, Miao F, Lau CN. Temperature dependence of the raman spectra of graphene and graphene multilayers. Nano Lett. 2007;7:2645-2469.

[54] Stephane B, Sunmin R, Louis E. Probing the intrinsic properties of exfoliated graphene: raman spectroscopy of free-standing monolayers. Nano Lett. 2009;9:346-352. 